\title{
A PEDAGOGIA DA INFÂNCIA COMO PERSPECTIVA PARA A FORMAÇÃO DE PROFESSORES: UM ESTUDO A PARTIR DO CURSO DE PEDAGOGIA DA FURG
}

\author{
S. R. V. GONÇALVES \\ Universidade Federal do Rio Grande - FURG \\ suzanevieira@gmail.com
}

Artigo submetido em outubro/2013 e aceito em agosto/2014

DOI: $10.15628 /$ holos.2014.1687

\section{RESUMO}

Este artigo apresenta os resultados de uma pesquisa desenvolvida no Núcleo de Estudo e Pesquisa em Educação da Infância - NEPE da Universidade Federal do Rio Grande - FURG, que teve como objetivo investigar a identificação dos estudantes matriculados no curso de Pedagogia com o campo de atuação profissional. 0 estudo foi desenvolvido considerando a nova organização curricular do curso de Pedagogia da FURG que foi alterada após a aprovação das Diretrizes Curriculares Nacionais - Resolução CNE/CP no. 1/2006, que extinguiram as habilitações e instituíram um novo perfil para a formação do pedagogo. A investigação situase no campo da pesquisa qualitativa e teve como sujeitos os estudantes que encontravam-se no quarto ano e último ano do curso de Pedagogia. Para coleta dos dados foram aplicados 56 questionários. Como ferramenta de análise dos questionários, adotou-se a metodologia da Análise Textual Discursiva, com a qual emergiram as categorias Infância e Profissão Docente. Desse modo, verificou-se que os estudantes revelaram possuir um forte sentimento de pertencimento com a profissão docente. Ainda foi revelada uma forte identificação com a infância, aspecto que possibilitou defender que o curso de Pedagogia pode promover a formação de professores da infância, pautado em uma Pedagogia da Infância que envolva o trabalho pedagógico com crianças de 0 a 12 anos.

PALAVRAS-CHAVE: Curso de Pedagogia, Formação de Professores da Infância, Pedagogia da Infância, identidade docente.

\section{THE CHILDHOOD PEDAGOGY WITH PERSPECTIVE AS TO TEACHER: A STUDY FROM THE PEDAGOGY COURSE AT FURG}

\begin{abstract}
This paper presents the results of a survey conducted at the Center for Study and Research in Childhood Education - NEPE Federal University of Rio Grande FURG, which aimed to investigate the identification of students enrolled in the Pedagogy course with the professional field. The study was developed considering the new curricular organization of pedagogy FURG which was changed after the approval of the National Curriculum Guidelines - CNE / CP no. 1/2006, which extinguished the qualifications and set up a new profile for the formation of the pedagogue. The research is in the field of qualitative research as subjects and had students
\end{abstract}

who were in the fourth and final year of Pedagogy. For data collection were applied 56 questionnaires. As a too of analysis of questionnaires, we adopted the methodology of Textual Discourse Analysis, which emerged with the categories and Childhood Teaching Profession. Thus, it was revealed that students have a strong sense of belonging to the teaching profession. Also revealed was a strong identification with the childhood aspect that enabled defend the pedagogy course can promote the training of teachers of children, based on a childhood pedagogy involving pedagogical work with children $0-12$ years.

KEYWORDS: Pedagogy course, Teacher Training for Children, Childhood Pedagogy, teacher identity. 


\section{INTRODUÇÃO}

Este trabalho apresenta os resultados de um estudo desenvolvido no Núcleo de Estudo e Pesquisa em Educação da Infância - NEPE da Universidade Federal do Rio Grande - FURG, que teve como objetivo investigar a identificação dos estudantes matriculados no curso de Pedagogia com o campo de atuação profissional. O estudo apontou uma forte identificação das estudantes com a área da Infância e indicou a possibilidade dos currículos dos cursos de Pedagogia assumirem uma formação pautada na Pedagogia da Infância.

A pesquisa ora apresentada está inserida no campo da investigação qualitativa. Tendo como referência os estudos de Bogdan e Biklen (1994), compreende-se que a investigação qualitativa pode assumir diversas formas tendo em vista os objetivos que pretende alcançar, mas sempre procurará compreender os fenômenos em sua complexidade e em contexto natural. A investigação foi compreendido como um estudo de caso, já que se propôs a analisar com profundidade uma unidade, no caso em tela o Curso de Pedagogia da FURG.

Desse modo, com a intenção de estudar uma situação específica e buscar entendimento sobre o que há nela de mais essencial e característico, e que se fez a opção de utilizar como procedimentos de coleta de dados a pesquisa bibliográfica e a aplicação de questionários.

Os dados foram coletados no primeiro semestre de 2011, com as estudantes matriculadas no quarto ano do curso de Pedagogia da FURG, dos dois turnos de oferta, manhã e noite. Participaram do estudo, respondendo os questionários, 56 estudantes de um total de 67, que representou $83 \%$ das acadêmicas do quarto ano. A intenção de coletar dados com os estudantes do último ano justificou-se por eles terem vivenciado o curso por mais tempo. O que oportunizou compreender qual a percepção que eles têm do currículo e do curso, bem como verificar de que formas eles se compreendem pertencentes ao curso, entre outros aspectos.

\section{O CURSO DE PEDAGOGIA DA FURG}

O Curso de Pedagogia da FURG, desde sua criação, passou por várias organizações curriculares, sempre definindo habilitações para os seus egressos. Desde 2007, devido à aprovação das Diretrizes Curriculares Nacionais da Pedagogia, o curso teve que assumir uma nova organização, pois a legislação propunha o fim das habilitações e a formação de um pedagogo com perfil generalista. Assim, a FURG reformulou seus cursos de Pedagogia, que na época, caracterizavam-se pela formação de professores para Educação Infantil e anos iniciais do Ensino Fundamental em cursos específicos, propondo a criação do Curso de Pedagogia-Licenciatura.

O Projeto Pedagógico do Curso justifica a criação do Curso de Pedagogia-Licenciatura principalmente em função das exigências legais, mas também afirma que é pautado nas "perspectivas de formação docente para este milênio e pelas necessidades apontadas pelos acadêmicos do curso" (2006, p.3). Assim, o desenho curricular proposto

[...] toma como base as constatações dos estudos apresentados acerca da formação docente e a problemática do ensino e da aprendizagem na Educação Infantil e nos Anos Iniciais do Ensino Fundamental, prioritariamente, mas também na Gestão Escolar. Assim, prevê a interação entre as disciplinas de cada Núcleo e 
a contextualização dos conhecimentos trabalhados nas mesmas com o cotidiano da ação docente. Neste novo desenho a ComCur de Pedagogia acredita ser também de grande relevância na formação do profissional que atua neste nível de ensino, os conhecimentos acerca da Educação de Jovens e Adultos, principalmente no que se refere à alfabetização, pois este docente também poderá ser solicitado a atuar nos programas da EJA. (Projeto Pedagógico do Curso de Pedagogia-Licenciatura, 2006, p. 6)

O desenho curricular proposto vai ao encontro do estabelecido nas Diretrizes Curriculares, pois com a extinção das habilitações pelo artigo 10 das diretrizes, os cursos de Pedagogia deverão assumir prioritariamente em seus currículos, a formação para a docência na Educação Infantil e nos anos iniciais do Ensino Fundamental, além de envolver outras áreas no âmbito da formação do pedagogo.

O curso foi proposto com a oferta de uma turma com 45 estudantes no turno da manhã e outra no turno da noite, tendo como perfil profissional exatamente o estabelecido no artigo 40 da Resolução CNE/CP no 1/2006. Considerando o perfil desejado, o objetivo do curso consiste em

Formar o Pedagogo para a docência na Educação Infantil e nos Anos Iniciais do Ensino Fundamental, nos Cursos de Ensino Médio, na modalidade Normal, e em cursos de Educação Profissional na área de serviços e apoio escolar e em outras áreas nas quais sejam previstos conhecimentos pedagógicos, buscando ainda desenvolver neste profissional, capacidades de gestão e de coordenação pedagógica para atuar em espaços escolares e não escolares. O curso propõe, também, contemplar a discussão sobre Educação de Jovens e Adultos a fim de possibilitar ao Pedagogo uma visão mais abrangente sobre o processo educacional brasileiro" (Projeto Pedagógico do Curso de Pedagogia-Licenciatura, 2006, p. 8).

O currículo do curso está organizado a partir de quatro núcleos, compostos por disciplinas, seguindo as orientações do artigo 60 da Resolução no. 1/2006. O tempo de duração do curso é de 4 anos e possui duas turmas, uma no turno da manhã e outra no turno da noite.

\section{GOSTAR DE CRIANÇA COMO DEFINIDOR DA ESCOLA PROFISSIONAL}

"Sempre gostei de crianças, e se um dia voltasse a estudar seria para Pedagogia". Estudante 6.

No estudo, um dos principais aspectos que possibilitaram compreender a infância como uma categoria que identifica as estudantes sujeitos dessa pesquisa com o curso de Pedagogia da FURG, foi o relato, da maioria delas, que afirmou que procuraram o curso por gostarem de criança e que pretendem atuar na Educação Infantil ou nos anos iniciais, com crianças.

A fala das acadêmicas que justifica a escolha pelo curso, pela futura área de atuação e sua identificação com a Pedagogia, por gostarem de crianças, remete-nos às discussões que envolvem a formação de professores e o trabalho docente na Educação Infantil e no antigo ensino primário, hoje anos iniciais do Ensino Fundamental. Tais estudos, apresentam indícios que evidenciam o quanto a docência nesses níveis de ensino foi, historicamente, constituindo-se como uma profissão feminina e o quanto as características socialmente atribuídas à feminilidade caracterizaram as 
profissionais que atuam como professoras da infância. Chamamos a atenção que todos os 56 estudantes participantes desta pesquisa são mulheres, aspecto que não pode ser ignorado quando tratamos da questão da feminização do magistério.

A história do trabalho docente, no Brasil e no mundo, é marcada pela questão de gênero, principalmente quando nos referimos às práticas educativas com crianças, em que a presença feminina é hegemônica, sendo socialmente reconhecida como uma profissão feminina. Esse fenômeno vem sendo chamado por muitos estudiosos de feminização do magistério (ENGUITA, 1991; HYPÓLITO, 1997).

A feminização do magistério ocorreu a partir de mudanças sociais, políticas e econômicas, fruto do advento do capitalismo e da reestruturação da sociedade que provocou a inserção das mulheres no mercado de trabalho. Essa inserção se dá a partir de vários fatores como: o novo papel assumido pelo Estado liberal, a necessidade de ampliação das escolas, a possibilidade de escolarização das mulheres, bem como as características femininas. Cabe destacar que esse movimento que inseriu as mulheres no mercado de trabalho alterou o seu papel na sociedade, no entanto sem garantir condições de igualdade em relação aos homens.

A possibilidade das mulheres saírem do ambiente doméstico para ingressarem no mercado de trabalho, exercendo uma profissão que de certa forma lhe oportunizaria uma certa autonomia, pode ser considerada uma vitória. Porém, verificou-se ao longo da história que com a participação massiça feminina no magistério, a profissão docente passa por uma crescente desvalorização econômica, aspecto que tem caracterizado as profissões ocupadas majoritariamente por mulheres.

O processo de feminização esteve vinculado ao desenvolvimento da industrialização e urbanização, provocados pela nova organização social advinda do modo de produção capitalista. Nesse contexto, as mulheres, a partir de suas características culturais e sociais, foram consolidando o perfil do professorado.

As características femininas que propiciaram o magistério ser identificado como uma profissão adequada para as mulheres estão relacionadas com o entendimento da atividade docente ser próxima das funções de mãe, a compreensão de que as mulheres possuem mais habilidades para cuidar de crianças, o ideário da vocação estar relacionado com as aptidões femininas e a possibilidade de compatibilizar as funções profissionais e domésticas. A estudante 1 afirma ter escolhido o curso "pelo fato de ter grande afinidade em conviver com crianças", justificativa que vai ao encontro da visão que evidencia a habilidade feminina em lidar com as crianças.

A partir da compreensão social dessas características femininas é que foi possível a aceitação na sociedade de que as mulheres poderiam exercer essa profissão. Além dos aspectos elencados acima, outros dois somam-se ao processo de feminização do magistério, a possibilidade de escolarização das mulheres em Escolas Normais e a saída dos homens do magistério para ocupar cargos melhor remunerados e com mais status no mercado de trabalho.

Neste contexto, autores como Enguita (1991) afirmam que a feminização do trabalho docente contribuiu para a desvalorização da profissão de professor. A docência, ao ser exercida pelas mulheres, deixa de valorizar os saberes técnicos e profissionais para naturalizar o trabalho 
exercido pelas mulheres como aptidões inatas. Nesse sentido, o trabalho realizado pelas mulheres é considerado inferior, pois não possui saberes profissionais.

Assim, o magistério vai sendo assumido como uma profissão feminina, pois representa a síntese "natural" entre vocação/ensino/maternidade/funções domésticas. Ao ser considerado como natural, já que na profissão se teria a extensão do cuidado com crianças, que acontece no âmbito da família, torna-se quase automático relacionar trabalho de professor com vocação feminina (HYPÓLITO, 1997). Essa relação de mãe e professora está presente na fala das alunas do curso de Pedagogia da FURG, a estudante 41 afirma que o principal motivo por ter escolhido o curso "foi meu interesse em me aprofundar na área da educação, após ter tido um filho".

No campo educacional, a concepção de cuidado no trabalho pedagógico com as crianças ganha espaço. Inicialmente, o conceito de cuidado estava vinculado às questões da maternagem, porém com a feminização do magistério, justificado pelas aptidões femininas, o cuidado infantil ultrapassa a esfera da vida privada.

A concepção de cuidado infantil não surge apenas com a inserção das mulheres na profissão docente, é fruto de uma série de mudanças que envolveram a construção de um sentimento de infância e um novo olhar sobre as crianças, bem como os avanços científicos relacionados com os estudos das áreas da Pediatria, da Psicologia e da Pedagogia, (CARVALHO, 1999). O conceito de cuidado está atrelado à concepção de feminilidade, uma vez que as mulheres são moldadas, a partir de características que pregam, pela afetividade e que envolvem, nos seus relacionamentos, o cuidado com o outro, em especial com as crianças. No trabalho pedagógico com crianças a concepção de cuidado acaba sempre se fazendo presente, com maior intensidade com as crianças menores, que frequentam a Educação Infantil.

A maioria das acadêmicas do curso de Pedagogia, ao enfatizarem que escolheram o curso por gostarem de criança, trazem em seu discurso implícita e explícitamente a questão do cuidado, quando afirmam terem afinidade com as crianças, por saberem cuidar de criança, terem jeito com crianças, conforme fica explícito na fala da estudante 36 "eu me identifico enquanto educadora de crianças pequenas, pois ao longo do curso e da minha trajetória percebo minha identificação com as crianças da Educação Infantil e o curso me possibilitou um entendimento da compreensão desse universo infantil".

Nesse sentido, para compreender as questões que envolvem o cuidado é importante considerar as mudanças sociais e históricas que envolveram as relações entre adultos e crianças. Neste texto, estamos supondo que foram essas transformações que contribuíram para que hoje se verifique que a ideia de gostar de criança é praticamente uma condição para o trabalho na Educação Infantil e nos anos iniciais do Ensino Fundamental.

O surgimento da imagem da criança como um ser que inspira cuidados, e a emergência de um sentimento de infância foi um fenômeno histórico e social que produziu, na Modernindade, transformações nas organizações familiares, nas instituições escolares e em outros espaços.

As transformações na ideia de criança, família e na própria organização pedagógica contribuem para que a escola assuma um novo rumo, aproximando sua identificação com a domesticidade e a ação docente na infância com a feminilidade. A instituição escolar deixa ser reconhecida como um lugar de distribuição de castigos e recompensas, com o papel autoritário do professor que detinha o conhecimento e o controle sobre a classe, para assumir-se como um 
espaço agradável, com sua atenção voltada para os interesses e necessidades das crianças, sendo reconhecida como uma extensão do lar e da família (CARVALHO, 1997).

Desse modo, são construídas socialmente imagens que marcam a diferença e os papéis atribuídos para homens e mulheres. Essas diferenças são trazidas para o interior da escola e irão interferir no fazer pedagógico, a domesticidade apresenta consequências ao funcionamento escolar. Podemos observar tanto na Educação Infantil, como nos anos iniciais do Ensino Fundamental que existe, marcadamente, uma maneira feminina de organizar o trabalho e relacionar-se com as crianças/alunos, assim, as práticas de maternagem passam a fazer parte da escola da infância.

Com isso, vão sendo definidos os padrões do bom professor de crianças, o qual precisa assumir as características tipicamente femininas. A boa professora deveria, então, apresentar 0 chamado instinto maternal, para que pudesse cuidar de seus alunos como uma segunda mãe. $O$ cuidado vai ocupando um papel importante no contexto escolar, na relação entre adultos e crianças, sendo um conceito construído social e historicamente na Modernidade, que também corrobora na construção das concepções de infância e na imagem de docência no ensino primário.

Todos esses aspectos, que procuramos discutir nessa seção, corroboram para pensarmos como a escolha da profissão, vinculada ao discurso do gostar de criança, está atrelado a fenômenos sociais, políticos e históricos que envolveram, principalmente, o papel das crianças e das mulheres na sociedade. A feminização do magistério e a suposta aptidão feminina para lidar com as crianças trouxeram reflexos na vida escolar e na constituição da identidade profissional docente.

A afetividade constitui-se como uma característica marcante na identidade das professoras que atuam com crianças, tanto na Educação Infantil como nos anos iniciais do Ensino Fundamental. Nesse sentido, entendemos que a fala das acadêmicas do curso de Pedagogia da FURG, ao se referirem que escolheram a profissão pela sua afinidade com as crianças, está entrelaçada às representações sociais sobre o papel de mulher.

\section{A PEDAGOGIA DA INFÂNCIA COMO EIXO DA FORMAÇÃO DO PEDAGOGO}

Como já referimos anteriormente, o trabalho docente na Educação Infantil e nos anos iniciais do Ensino Fundamental tem sido desenvolvido, prioritariamente, por mulheres, e a formação destas tem se dado em cursos Normais, em nível médio, e em cursos de Pedagogia, em nível superior. Por muito tempo, esses cursos focalizaram a formação de professores primários, pois o trabalho com as crianças menores de 6 anos não era legalmente reconhecido como do campo da Educação.

Ainda que, no debate educacional se defendesse o aspecto educativo das creches e préescolas, foi a partir da LDB que, legalmente, estas foram consideradas da área da Educação, sendo reconhecidas como a primeira etapa da Educação Básica. Cabe lembrar, que no Brasil, as creches surgiram com um caráter assistencialista, com o objetivo de assistir os filhos de mães trabalhadoras. $O$ foco do atendimento oferecido era o cuidado com relação à alimentação, higiene e segurança física. Como não havia prioritariamente uma preocupação educativa nestas instituições, o trabalho, na maioria das vezes, não era desenvolvido por professores.

O processo de expansão da Educação Infantil no Brasil, a partir da década de 1980, esteve atrelado às reivindicações dos movimentos sociais e às lutas dos movimentos feministas, bem 
como às discussões das grandes Conferências Nacionais de Educação, à promulgação da Constituição, em 1988, do Estatuto da Criança e do Adolescente e, posteriormente, em 1996, com a aprovação da Lei de Diretrizes e Bases da Educação Nacional. Tais dispositivos legais garantiram o direito à educação, às crianças de 0 a 6 anos e, consequentemente, impuseram ao Estado a obrigatoriedade em oferecer instituições, no âmbito do sistema escolar, para essa faixa etária (KISHIMOTO, 1999).

A formação de professores para Educação Infantil, bem como para os anos iniciais do Ensino Fundamental, pode ser realizada em cursos Normais em nível médio ou pós-médio profissionalizante ou em cursos de graduação em Pedagogia. Desde a aprovação da LDB, os cursos Normais têm oferecido uma dupla formação para a docência nos dois níveis de ensino, já os cursos de Pedagogia, até a aprovação das suas Diretrizes Curriculares, possuíam habilitações e a formação oferecida, na maioria das universidades, priorizava o trabalho nos anos iniciais e nem sempre era oportunizada a formação em uma habilitação para Educação Infantil.

Os cursos de graduação em Pedagogia, que habilitavam para o trabalho docente na Educação Infantil, buscavam, por meio de seu currículo, em sua maioria, uma formação que valorizasse a infância, o trabalho com a ludicidade, as brincadeiras e as linguagens, e que focasse na indissociabilidade entre cuidado e educação, aspecto que pode ser veríficado no curso de Pedagogia - Educação Infantil, da FURG. Já o currículo para a docência para os anos iniciais do Ensino Fundamental apresentava suas discussões voltadas para a escolarização, com práticas que valorizam mais os conteúdos conceituais do Ensino Fundamental do que os interesses e necessidades das crianças que frequentam esse nível de ensino, também verificado no curso de Pedagogia - anos iniciais, da FURG.

Reconhecemos que ambos os níveis de ensino possuem objetivos e especificidades para o trabalho pedagógico a ser desenvolvido, porém os dois realizam suas práticas para crianças, e deveriam se atentar às necessidades da infância. Estudos realizados por autores como Nogueira (2011); Faria (2007) e Albuquerque e Protásio (2005), apontam a importância de uma articulação entre os dois níveis de ensino, com o intuito de amenizar as rupturas que a transição de um nível para o outro geram. Uma das propostas que estes autores indicam é que se pense em uma Pedagogia da Infância, que considere o trabalho pedagógico com as crianças de 0 a 12 anos.

Até a aprovação das Diretrizes Curriculares para o curso de Pedagogia, em 2006, podemos considerar que a formação de professores oferecida na maioria das universidades era bastante dicotômica, voltada para as especificidades dos anos iniciais ou da Educação Infantil, ainda haviam cursos que habilitavam para Educação Especial ou direcionavam seus currículos para a formação dos especialistas. Com as novas diretrizes, em que se findaram as habilitações, a formação de professores para os dois níveis, num mesmo curso, passou a ser uma realidade e exigiu das Instituições de Ensino Superior uma reorganização de seus currículos, que atendessem as novas exigências legais. Se por um lado, o novo currículo dos cursos de Pedagogia tem sido bastante criticado por assumir um caráter generalista para a formação de professores, por outro lado possibilitou que se pense a formação dos professores para Educação Infantil e anos iniciais com um olhar para as infâncias e de modo mais articulado, sem perder as especificidades de cada nível.

Freitas (1999), ao discutir a reforma do Ensino Superior no campo da formação dos profissionais da Educação Básica, defende que os cursos de Pedagogia, no âmbito das faculdades e centros de educação, 
tem permitido seu aprimoramento e aperfeiçoamento na direção de tomar a prática educativa e a educação como objeto de estudo na formação de profissionais para atuação na educação básica - na formação de crianças de 0 a 10 anos -, identificando, no trabalho pedagógico escolar e não-escolar, elementos constitutivos da formação humana em sua dimensão omnilateral (1999, p. 27-28)

Com a aprovação das Diretrizes do Curso de Pedagogia, a formação de professores da Educação Básica para o trabalho com crianças de 0 a 10 torna-se legalmente uma realidade nos cursos de Pedagogia, já que antes acontecia em uma ou outra universidade. Embora, não possamos afirmar que as Diretrizes do Curso de Pedagogia apontam na direção de uma Pedagogia da Infância, até porque nem nos pareceres e nem na resolução, essa expressão aparece. No entanto, é inegável que ao proporem a formação de um mesmo profissional para atuar nos dois níveis, abriu-se o caminho para que os currículos tenham como foco uma Pedagogia da Infância.

Para Scheibe (2007, p. 60), as Diretrizes Curriculares para o Curso de Pedagogia o definiram como uma "licenciatura para a docência polivalente, requerida para a educação/escolarização de zero a dez anos". Ainda, para a autora,

A formulação aprovada prevê, pelo menos no interior da formação para o atendimento às crianças de zero a dez anos, e da docência que implica os processos de alfabetização nas diversas áreas do conhecimento, uma base comum: a formação integrada do professor para educação infantil e anos iniciais do ensino fundamental. Esta é também a base necessária às outras funções a que se propõe o curso.(2007, p. 60)

O debate, entre os pesquisadores, a respeito da Pedagogia da Infância não é algo recente. Diferentes autores têm utilizado esse termo para chamar a atenção dos gestores educacionais e professores sobre a importância de termos práticas educativas que considerem o direito das crianças à educação, a partir dos interesses e necessidades das infâncias. Algumas autoras como Cerisara (2005), Rocha $(1999,2003)$ iniciam o debate acerca da Pedagogia da Infância destacando a importância de uma pedagogia para Educação Infantil, discutindo que o trabalho educativo com as crianças pequenas vai além do cuidado. Outras autoras, como Campos (1999), Albuquerque e Protásio (2005), Faria (2007), contribuem para pensar a articulação entre Educação Infantil e anos iniciais, priorizando o respeito ao direito de ser criança em ambos os níveis de ensino.

Neste trabalho, entendemos que refletir sobre uma Pedagogia da Infância e, consequentemente, sobre a formação de professores da infância, pressupõe o reconhecimento das crianças como sujeitos de direitos, que vivenciam diferentes infâncias em tempos e espaços sociais diversificados, considerando o contexto de vida mais imediato das crianças, suas necessidades, peculiaridades e diferenças culturais, étnicas e de gênero. Requer, também, que se pense para além das fronteiras institucionais, que separam a Educação Infantil do Ensino Fundamental e vice-versa, sem perder de vista as especificidades que os constituem. Cabe destacar que o que se pretende com uma pedagogia da infância não é a inclusão de práticas próprias da Educação Infantil nos anos iniciais do Ensino Fundamental e nem o inverso, com a uniformização de práticas escolares ou a antecipação dos conteúdos (CERISARA, 2002). Pretende-se que cada um das etapas de ensino, respeitando suas especificidades, possam ser receptivos às crianças que neles ingressam. 
É comum, ao se falar em infância, associar essa apenas com a Educação Infantil, que faz o atendimento de crianças entre 0 e 6 anos de idade. Porém, o Estatuto da Criança e do Adolescente (ECA) define que a infância compreende as crianças de 0 a 12 anos, ou seja, em termos educacionais, compreende a Educação Infantil e o primeiro segmento do Ensino Fundamental. É, nesse sentido, que entendemos que a Pedagogia da Infância pode acontecer, desenvolvendo processos educativos que contemplem, o cuidado, a educação e a inserção social da criança, tendo em vista suas singularidades, peculiaridades e diferenças inerentes à faixa etária em que se encontram.

O que se pretende com a Pedagogia da Infância é, que as práticas de cuidado e educação ocorram como ações complementares e, que as propostas pedagógicas considerem a criança como um ser completo em suas dimensões cognitivas, afetivas, psicomotoras e sociais.

O debate a respeito da importância de se pensar uma articulação entre Educação Infantil e anos iniciais do Ensino Fundamental, a partir de um Pedagogia da Infância, também ganhou força com a aprovação da Lei $n^{\circ} 11.274 / 2006$, que instituiu o ensino Fundamental com nove anos de duração e o ingresso das crianças de seis anos nesse nível. Esse novo dispositivo legal, colocou em tela uma grande discussão no meio educacional acerca da organização do trabalho pedagógico nos anos iniciais do Ensino Fundamental, pois a ampliação do mesmo para nove anos não implicou a criação de uma nona série, mas sim a supressão do último ano da Educação Infantil.

Alguns estudos (CAMPOS et. al, 2011; FARIA, 2007), ao problematizarem a nova organização do Ensino Fundamental e as repercursões da ampliação para nove anos, com o ingresso das crianças de seis anos no Ensino Fundamental, contribuem para pensarmos na urgência de instituírmos na formação de professores e nas próprias escolas, uma Pedagogia da Infância. Campos et al (2011) alertam para a importância de considerarmos as experiências educativas vivenciadas pelas crianças, na Educação Infantil, ao ingressarem no Ensino Fundamental, destacando a necessidade de se pensar a transição entre esses níveis de ensino. Alerta, ainda, que a transição entre os níveis, não se trata de exigir que a Educação Infantil prepare as crianças para o ingresso no Ensino Fundamental, mas que o Ensino Fundamental seja receptivo às crianças que nele ingressam.

Para Faria (2007) o ingresso das crianças de seis anos no Ensino Fundamental trouxe profundas transformações na escola e no sistema de ensino, implicando modificações, também, na formação docente. Para a autora, aspectos já discutidos acerca do trabalho pedagógico na Educação Infantil, como as questões de infraestrutura e da organização do espaço físico, que envolvem uma pedagogia da escuta, uma pedagogia das relações, uma pedagogia das diferenças, podem ser construídos, em continuidade com os anos iniciais, se tivermos uma articulação entre os níveis de ensino.

Podemos observar que, se com o ingresso das crianças de sete anos no Ensino Fundamental já havia uma preocupação acerca da organização do tempo, do espaço e das metodologias de ensino, considerando as significativas diferenças entre a Educação Infantil e o Ensino Fundamental, com o ingresso das crianças de seis anos no primeiro ano do Ensino Fundamental a preocupação tornou-se maior, uma vez que as crianças são, ainda, menores.

A Pedagogia da Infância envolverá, a sensibilidade da escola e dos professores para compreenderem e incorporarem a cultura infantil em seu projeto pedagógico, buscando articular as lógicas infantis com às lógicas educativas. Desse modo, o que se requer dos professores é que 
estes estejam atentos as falas, sentimentos e brincadeiras das crianças, para que, por meio da compreensão da forma como se relacionam entre elas, com a escola e com os próprios saberes, possam desenvolver uma prática educativa mais interessante (ALBUQUERQUE E PROTÁSIO, 2005). Desse modo, construir um currículo para uma pedagogia da infância, centrada na criança de 0 a 10 anos, requer pensar em continuidade entre o currículo da Educação Infantil e o currículo dos anos iniciais, considerando as especificidades das experiências vividas pelas crianças e atento para as diversas formas de organização do pensamento, durante a infância (CAMPOS et al, 2011).

Assim, o que necessitamos é uma formação docente voltada para a infância, que procure garantir a continuidade da educação para as crianças de todas as idades, respeitando as especificidades dos sujeitos e os objetivos dos níveis educacionais. Entendo que a discussão acerca da constituição de uma Pedagogia da Infância passa pelo debate da identidade do curso de Pedagogia e a formação oferecida por este.

Cabe destacar que não basta gostar de criança para ser professor, essa visão, na maioria das vezes, atrelada à ideia de vocação, contribui para que a profissão docente seja desvalorizada em nossa sociedade. Ao mesmo tempo, o gostar de criança e da profissão, são aspectos importantes da profissão docente, porém, são necessários outros aspectos para se ter um "bom" profissional. Entre esses aspectos está a formação, que precisa ser sólida, com compromisso com a produção de conhecimentos científicos, culturais e artísticos.

\section{CONSIDERAÇÕES FINAIS}

Por fim, queremos reafirmar que nos termos do que estamos discutindo neste trabalho, talvez possamos apontar que as DCN podem ser vistas positivamente, por potencializar a formação de um professor da infância, já que em um mesmo curso está preparando o professor da Educação Infantil e dos anos iniciais, ou seja, um profissional que atuará com crianças de 0 a 12 anos de idade.

Em 2006, com a aprovação das novas Diretrizes Curriculares para o Curso de Pedagogia, todas as universidades iniciaram um processo de reformulação de seus cursos, buscando atender às novas exigências legais. As atuais diretrizes ampliaram o campo de atuação do pedagogo e propuseram uma formação única com o fim das habilitações.

Tal fato tem levado a uma série de discussões acerca dos rumos da formação do pedagogo, envolvendo questões relativas à identidade desse novo profissional generalista, à possível superficialidade da formação sem habilitações entre outros aspectos atinentes à formação desse profissional.

O pertencimento à infância pode ser compreendido como fruto do interesse das estudantes nas questões que envolvem o trabalho com crianças, o gosto por elas e a identificação que elas vão construindo ao longo do curso, com o trabalho na Educação Infantil e nos anos iniciais do Ensino Fundamental. Tal interesse, não aparece do nada, cremos ser fruto de uma construção histórica e social, como procuramos mostrar neste artigo, em que as mulheres foram, hegemonicamente, assumindo a docência com crianças, face suas ditas características maternais, afetivas e dóceis.

Temos convicção que o papel dos professores neste novo cenário educacional é fundamental, e a formação de professores precisará dar conta dessas discussões em seu currículo, 
com vistas à formação de professores da infância. Entendemos que a formação docente nos cursos de Pedagogia pressupõe a construção de uma concepção de infância e de criança como sujeito histórico-social e de direitos, que é ativo na produção de conhecimentos e culturas.

\section{REFERÊNCIAS}

1. AlBUQUERQUE, Simone Santos de e PROTÁSIO, Michele Reinaldo. Quando as Crianças Passam a ser alunas? problematizações sobre a articulação da Educação Infantil e os anos iniciais do Ensino Fundamental. In: Revista Momento, Rio Grande, 17: 95-106, 2004/2005.

2. BRASIL. CONSELHO NACIONAL DE EDUCAÇÃO. Resolução 1/2006. Institui Diretrizes Curriculares Nacionais para o Curso de Graduação em Pedagogia, licenciatura. Maio de 2006. Disponível em <http://mec.gov.br/cne> Acesso em 2 de junho de 2006.

3. BOGDAN, Robert.C; BIKLEN, Sari Knopp. Investigação Qualitativa em Educação: uma introdução à teoria e aos métodos. Porto: Porto Editora, 1994.

4. CAMPOS, Maria Malta. A Formação de professores para crianças de 0 a 10 anos: modelos em debate. Educação \& Sociedade, v.20, n.68, p.126-142, dez. 1999. (Número especial: Formação de profissionais da educação: políticas e tendências.)

5. CAMPOS, Maria Malta et al. A qualidade da educação infantil: um estudo em seis capitais Brasileiras. Cadernos de Pesquisa. [online]. 2011, vol.41, n.142, pp. 20-54. Disponível em: http://www.scielo.br/scielo.php?script=sci_arttext\&pid=S0100-

15742011000100003\&lng=en\&nrm=iso\&tIng=pt Acesso em 30 de junho de 2012.

6. CARVALHO, Marília Pinto de. Trabalho docente e relações de gênero: algumas indagações. Revista Brasileira de Educação. n. 2, p. 77-84 , Mai/Jun/Jul/Ago, 1996.

7. N N No coração da sala de aula: gênero e trabalho docente nas séries iniciais. São Paulo: Xamã/ Fapesp, 1999.

8. CERISARA, Ana Beatriz. Referencial curricular nacional para educação infantil no contexto das reformas. Educação \& Sociedade, v.23, n.80, p.329-348, 2002.

9. _ـ A produção acadêmica na área da Educação Infantil com base na análise dos pareceres sobre o Referencial Curricular nacional da Educação Infantil: primeiras aproximações. In: FARIA, Ana Lucia Goulart de; PALHARES, Marina Silveira. (Orgs.). Educação Infantil Pós- LDB: rumos e desafios. Campinas-SP: Autores Associados, 2005.

10. ENGUITA, Mariano. A ambigüidade da docência: entre o profissionalismo e a proletarização. Teoria \& Educação. Porto Alegre, n. 4, 1991.

11. FARIA, Ana Lúcia Goulart de. Para uma pedagogia da infância. Revista Patio Educação Infantil, Porto Alegre: Artmed Editora, n. 14, p. 6-9, Jul/Out 2007.

12. FREITAS, Helena Costa Lopes de. A reforma universitária no campo da formação dos profissionais da educação básica: as políticas educacionais e o movimento dos educadores. Educação \& Sociedade, Campinas, v. 20, n. 68, dez. 1999. Disponível em: www.scielo.br/pdf/es/v20n68/a02v2068.pdf Acessado em 20 de junho de 2012.

13. FURG. Projeto Político-Pedagógico do Curso de Pedagogia - Licenciatura. 2006. Mimeo.

14. HYPOLITO, Álvaro M. Trabalho docente, classe social e relações de gênero. Campinas: Papirus, 1997. 
15. KISHIMOTO, Tizuko Morchida. Política de formação profissional para a educação infantil: pedagogia e normal superior. Educação \& Sociedade, Campinas, v. 20, n. 69, p. 61-79, 1999. Disponível em: www.scielo.br/pdf/es/v20n68/a04v2068.pdf Acesso em 10 de janeiro de 2012.

16. KRAMER, Sonia. A política do pré-escolar no Brasil: a arte do disfarce. 5. ed. São Paulo: Cortez,1995.

17. KUHLMANN JR., Moisés. Histórias da educação infantil brasileira. Revista Brasileira de Educação, n.14, mai-ago, 2000. pp.5-18. Disponível em: www.anped.org.br/.../RBDE14_03_MOYSESKUHLMANN_JR.pdf Acesso em 30 de maio de 2012.

18. LOURO, Guacira Lopes. Gênero, sexualidade e educação: uma perspectiva pós-estruturalista. Petrópolis: Vozes, 1997.

19. MEDEIROS, Ivone Regina. CURSO DE PEDAGOGIA DA FURG: um estudo sobre a influência da formação na atuação da profissional egressa. Dissertação de Mestrado.1999. Programa de Pós-Graduação em Educação da Universidade Federal de Pelotas. Pelotas, RS,1999.

20. NOGUEIRA, Gabriela Medeiros. A passagem da educação infantil para o 1 ano no contexto do Ensino Fundamental de nove anos: um estudo sobre alfabetização, letramento e cultura lúdica. Tese de Doutorado. Programa de Pós-graduação em Educação. Universidade Federal de Pelotas. 2011.

21. PASCHOAL, Jaqueline Delgado e MACHADO, Maria Cristina Gomes. A História da Educação Infantil no Brasil: avanços, retrocessos e desafios dessa modalidade educacional. Revista HISTEDBR On-line, Campinas, n.33, p.78-95,mar.2009. Disponível em: www.histedbr.fae.unicamp.br/revista/.../art05_33.pdf Acessado em: 15 de junho de 2012.

22. ROCHA, Eloisa Acires Candal. A pesquisa em Educação Infantil no Brasil: trajetória recente e perspectiva de consolidação de uma Pedagogia da Educação Infantil. Tese de doutorado. Programa de Pós Graduação em Educação. Universidade Estadual de Campinas, 1999.

23. A Pedagogia e a Educação Infantil. In: Revista Brasileira de Educação. Jan/Abr; no 16, 2001. pp. 27-34. Disponível em: www.anped.org.br/.../RBDE16_05_ELOISA_ACIRES.pdf Acessado em 20 de maio de 2012.

24. _. A função social das instituições de educação infantil. Revista Zero a Seis. Número 7. Janeiro/Junho de 2003.2 Disponível em: http://www.periodicos.ufsc.br/index.php/zeroseis/article/viewFile/799/9390 Acessado em 09 de dezembro de 2011.

25. SCHEIBE, Leda. Diretrizes curriculares para o curso de pedagogia: trajetória longa e inconclusa. In: Cadernos de Pesquisa, v. 37, n. 130, p.43-62, jan./abr. 2007. 